\title{
Training Kindergarten Teachers with Virtual Reality
}

\author{
David Passig and Tali Noyman \\ School of Education, Bar Ilan University, Ramat-Gan 52900, Israel \\ passig@mail.biu.ac.il
}

Keywords: virtual reality, teacher training, simulation

\begin{abstract}
In this study we used Virtual Reality to simulate a toddler's first few days' experiences in kindergarten and test whether we can improve the teacher's understanding of a toddler's feelings. The virtual worlds were developed in accordance with the toddler's way of emotional, cognitive and visual thinking. The participants in this study were 40 teachers who work with infants aged 6 months to 4 years old. The findings indicate that experiencing a virtual world that reflects the real world of children improves the teacher's awareness to the emotional experiences that a toddler undergoes in her/his first days in day-care or kindergarten.
\end{abstract}

\section{INTRODUCTION}

The emotional competencies of the child are very different from those of an adult. These competencies affect the way the toddler cope with the new environment. Erickson (1950) describes eight stages in the emotional development of a child. The first stage is the development of trust and confidence. In this stage the child will express trust in his caregivers if his needs will be fulfilled, such as warmth, love, and nourishment. On the other hand, the child will express mistrust if those needs will not be provided. The level of trust depends on the maternal attitude that he will receive. The parents should represent for the child a deep belief that there is a meaning to what ever they are doing for him (Erickson 1950).

Srof, Kooper and Dehart (1998) introduced a different emotional aspect that develops with toddlers. When a toddler starts recognising people as well 
as various items and develop expectation the child begins experiencing negative attitudes toward strangers (7-10 months). This fear from strangers might stretch a few months that can be prolonged to the second year. Therefore, when the toddler enters the day-care at that stage they will probably develop anxiousness to the new faces around (Shechter and McKolic 1989, Tal 1991).

Moreover, toddler's abilities to think and perceive are different from those of an adult, thus influencing the way in which they will adjust to a new place. The toddler's world outlook is absolute. Infants mix their 'self with the world, and only later do they distinguish between their private point of view and that of other individuals. Toddlers believes that they are the centre of everything that takes place, and that things always remain as they sees them (Piaget 1967). Even when their thought progresses to the preoperational stage (from 2 to 7 years), it is with difficulty that the toddler learns to see from someone else's viewpoint. Their thought is concrete things are as they seem from their direct and egocentric perception, and unsubstantial phenomena appear to them as tangible (dreams, thoughts) (Flavell 1970).

Toddlers egocentricity leads to Magi-like thoughts. They believe that their wishes, thoughts, and the words they emit from their mouth are the tools of their super-powers. When toddlers are at the stage at which they believe that they are omnipotent, and that it is within their power to sway their influence over every object in their environment, their entrance into a new framework shakes this belief: Suddenly events are out of their control, they do not understand them, and they are not sure that their needs will be met; feelings of fear and anxiety are awoken in them.

The assumption at the basis of this study, therefore, was that the caregiver does not possess enough awareness of the influence that the separation from parents has over a toddler's behaviour at the beginning of the year in the kindergarten.

By using $3 \mathrm{D}$ VR worlds that simulate mental aspects unique to toddlers, this study investigated whether it is possible to increase the teacher's awareness to the toddler's emotional experiences in their first days at the kindergarten. To the best of our knowledge, this is the first time that VR technology has been used in training toddlers' teachers, and in simulating toddlers' emotional experiences.

VR is defined as a computer-based immersive environment with a high level of interactivity (Pantelidis 1994). For this research, an experiment was carried out with the help of a virtual world that acted according to the rules of toddlers' cognitive and emotional development, and simulated toddlers' worlds for the caregiver. Studies carried out in other fields have indicated 
that the use of simulation can help to improve comprehension in various areas (Psotka 1995, Cass and Roblyer 1999).

We designed 3D VR worlds, in which we embedded cognitive and emotional elements from toddlers' experiences, based on Piaget's theories. The following is a description of the worlds, with an ascription of the various images to the emotional and cognitive aspects upon which they were based. These VR worlds can be accessed through the Internet with a free downloadable VR plugin http://faculty.biu.ac.il/ passig/vrprojects.html KINDERGARTEN).

\subsection{Object constancy}

The caregiver (in this case female)) enters a forest. Before her, she sees paths leading to further paths that lead to a house. After a few moments, different objects connected to the child's world start to fly past at speed. The objects swiftly and randomly approach and disappear. In the background, unclear sounds can be heard, interspersed with a number of clear words. From time to time, the user sees bodily parts approach and then recede. The user moves, and sees everything from the height of a child. The participant has to reach the house. She is not given any instructions. She needs to experience it on her own. If she finds herself unsuccessful, she must conclude that she needs to ask for assistance.

According to Piaget, the appearing and disappearing objects and voices reflect the developmental element of object constancy. According to Piaget (1967), up until the age of 8 months, infants think that if a certain object disappears from sight then it no longer exists. Only when infants are about one year old do they start to look for hidden objects, but even then they will look in the first place that the object was hidden. Only as toddlers reach the age of two years old do they learn that objects that cannot be seen still continue to exist. As a result, toddlers feel a sense of instability, living as they does in a world in which objects and people appear and disappear, and it is not clear what is going on around them. They live with a feeling that they lack control over their environment. Searching for the house via the paths represents the way the infant experiences things and learns - by trial

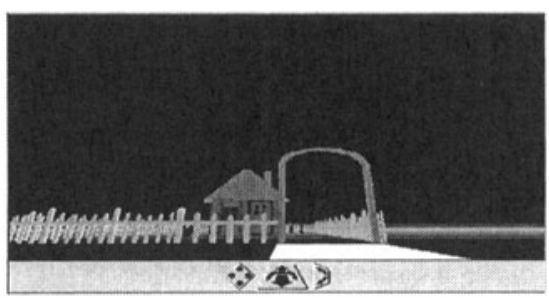
and error (Flavell 1970).

Figure 1. A picture from the virtual world the house in the forest that the user must reach 


\subsection{Trial and error}

Upon reaching the house, the caregiver enters a room. The room is a playroom in a kindergarten. Once more, the participant sees everything from the toddler's perspective. In the centre of the room a maze appears. The participant must pass along all of the maze's paths until she reaches the exit. She must knock over the cones that she encounters along the way. Because of the change in perspective, each time the user touches a cone, it changes shape. This also relates to the element of spatial perspective (objects) - the child perceives the object differently from each angle. When the teacher participant leaves the maze, she sees a door in front of her. She must touch the door, and move in to the next room. The attempt to find the way through the maze reflects the way the infant experiences things and learns - by trial and error (Flavell 1970).

Figure 2. The maze in the virtual world's playroom as seen from outside

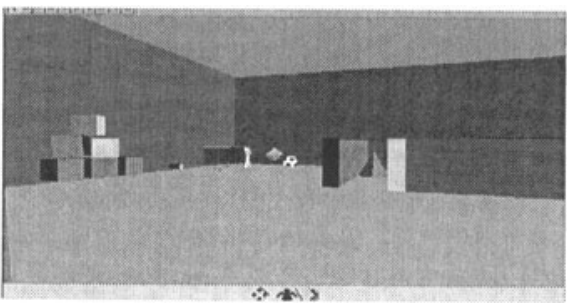

\subsection{Spatial perspective - height and objects}

The second room is designed like a playground. The participant can see a slide ahead of her. She is not given any instructions, and she must try to work out what to do alone, or ask for assistance. The participant must climb the ladder and slide down the slide. When she looks at the slide she can only see certain parts of the people and objects around her - she cannot see them in their entirety. After sliding down the slide, the participant will see big balls. She will struggle to catch them. The balls will roll away from her, until they disappear from her field of view, as if they no longer exist. After a number of attempts, a door will once more appear on the other side of the playground. The participant must touch the door and enter the next room. The teacher's attempts at catching the elusive balls once more reflect the element of trial and error. The rolling balls, escaping and disappearing from the user's field of vision, represent the developmental element of object constancy.

Figure 3. Part of the slide's ladder in the playground in the virtual world - view from below

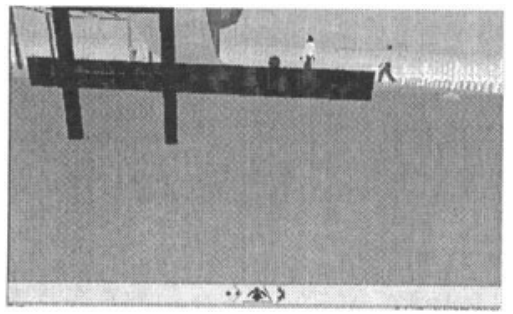




\subsection{Imagination and reality}

In the third room, the participant can see a rug with toys on it, a vacuum cleaner and a drill. For the whole length of this room's experience, the sound of the drill can be heard. The teacher looks around her and sees the drill in action, rotating, making an exaggerated noise, and making enormous holes. When the drill ceases to work, the vacuum cleaner comes on. At this moment its dimensions enlarge and expand, it makes noise, and sucks up every object in its path.

This experience represents the toddler's inability to fully distinguish between imagination and reality. According to Piaget (1967), the infant tends to attribute Magic importance to his/her thoughts. The infant thinks they can change reality with a word or a look, and also attributes human characteristics to inanimate objects. The vacuum cleaner, for instance, can 'eat' everything - objects and people (Piaget 1967).

Figure 4: The drill in action in the virtual world's third room

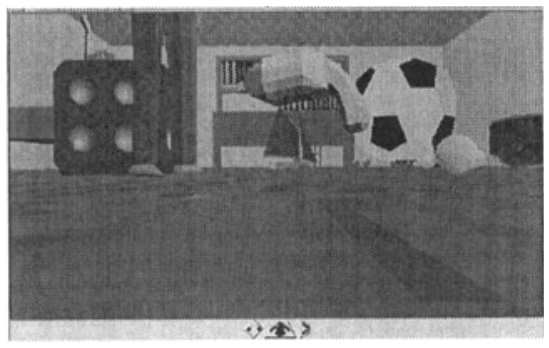

\subsection{Egocentricity}

While experiencing the virtual world, the participant wears a Head Mounted Display (HMD) and enters another world - the world of children. Throughout the experience, an effort is made to give the user the feeling that she is the centre of this virtual world - everything happens around her. She is required to activate the virtual world, otherwise, nothing happens; there are no people there other than her. Everything happens only to her and not to anyone else. The participant does not receive a description of what will happen to her during the experiment, but only a general explanation, and that in order to create a feeling of expectation, curiosity, and impatience to reach the next stage. This represents the infant's egocentricity. According to Piaget (1967), toddlers feel as if everything that happens is centred on them, and that they are at the centre of the world. They cannot see from another's point of view, and finds it hard to delay satisfaction (Piaget 1967). 


\section{THE RESEARCH}

\subsection{Participants}

The sample included 40 female teachers (Table 1.). The term 'teacher' relates to baby-minders and caregivers who work with infants aged 6 months to 4 years old in different private kindergartens under the supervision of the Ministry of Education..

Table 1. The sample of participants

\begin{tabular}{lllll}
\hline Age & $\mathbf{2 0 - 2 8}(n=12)$ & $29-41(n=14)$ & $\mathbf{4 2 - 5 8}(n=14)$ & Total $(\mathrm{n}=40)$ \\
\hline \multirow{3}{*}{ Education } & 6 did not & 14 completed & 19 studied & 1 did not \\
& finish high & 12 years of & between 13-17 & respond \\
& school & K12 education & years & \\
\hline
\end{tabular}

\subsection{Design}

After the VR worlds had been built, the researchers scheduled personal meetings at the caregivers' convenience. The meetings usually took place in the afternoon when the caregiver had finished work. Two to four caregivers participated in each meeting, each of which lasted between 2 and 3 hours. The researchers brought the hardware and software needed to run the virtual worlds to the kindergarten.

The research design included a pre-test, an experience in the VR worlds and a post-test. The researchers did not believe that a comparison with a control group that learned the cognitive state of mind, say through videotape, would be credible.

\subsection{Pre-experiment questionnaire}

Each participant received a short written explanation of what was about to happen. Each teacher was interviewed (questions $1-4$ in Table 2), and was asked about her opinions as to ways in which infants cope with their entrance into a new environment, and their reactions to it. Through the interview, the caregiver's level of awareness as to the effect of the toddler's separation from his parents on his behaviour before intervention was also tested. 
Table 2. Pre-experiment interview

1. What situations, in your opinion, can cause a child to be irritable, and not calm?

2. A child is not without his comfort blanket and dummy for a week at the beginning of the term. How would you react? Why?

3. A child chooses to sleep all the time. What would you do? Why?

4. About a month after the beginning of the year, a child still regularly bursts out crying. What should be done? Why?

Additionally, each caregiver was asked to fill out a questionnaire (Table 3 , questions 5-14). The caregiver was asked to react to a variety of situations. The questionnaires of this study were comprised with the help of infants' experts from the Baker Centre, Bar-Ilan University, Israel, since no adequate questionnaires were found to meet the purpose of this research. The experts from the Baker Centre who specialize in infants' development found this questionnaire suitable to the aims and procedures of this study.

Table 3. Pre-experiment questionnaire

5. An irritated child that cries frequently. How would you address him/her?

6. A child holds a blanket that he brought from home and does not want to separate from it. Should you do something? If yes, what would you do? Why is he behaving that way, in your opinion?

7. A child prefers to sleep during the activity times? Should you react? If yes, how?

8. A child starts crying whenever someone approaches him? What should you do? Why is he behaving that way, in your opinion?

9. A child does not want to leave his bottle? Should you react? If yes, what in your opinion you should do during the day-care time and at home?

10. A child sits in the corner and watches the activity with a serious look. Should you do something? If yes, what would you do?

11. A child throws items all over the room. What would you do? Why is he behaving like that, in your opinion?

12. A child prefers playing solo, and doesn't want to join others. Should you do something? If yes, what can you do?

13. A child holds on one of the caregivers and doesn't want to leave her and play around. How would you react, and what can be done?

14. A child hits and bites other kids in his surrounding. Should you react? If yes, what should you do?

\section{$2.4 \quad$ Virtual experience}

After completing the questionnaire, the researchers formed two groups of caregivers. One group experienced the virtual worlds without any emotional mediation, i.e., the researchers explained to each caregiver that she is about to enter a child's world, that no explanations or instructions will be given during the experiment, and that if she wants to know what to do, she must ask for help (Figure 5). This kind of introduction was given to just $20(n=40)$ of the participating caregivers. The other group was introduced to the 
experiment with emotional assistance. The researchers used a process of emotional mediation towards this group when after the caregiver put the helmet on, the researches reflected her feelings of helplessness in the VR

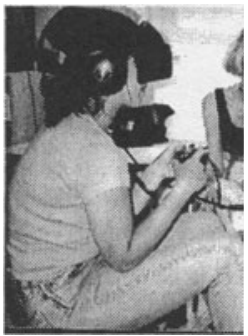
children world. They emphasized their empathy with her difficulties, and finally offered her assistance. The researchers told the caregiver that she could ask for any kind of assistance whenever she likes to.

Figure 5. A participant wearing the Head Mounted Display (HMD) and using the joystick whilst experiencing the virtual world

Each experience took about ten minutes. Many of the caregivers struggled to get by in the virtual world using the joystick. Very few asked for help, even when they did not ask what to do in each room in the virtual world the researchers assisted in their navigation and provided guidance.

\subsection{Post-experiment interview}

After the experiment, the caregivers were interviewed. They were asked about their feelings during and following their experience. The aim was to verify whether the caregiver experienced anxiety, frustration and the need for help during the experiment. Another objective was to verify whether the experience would affect her attitude towards a newcomer infant to her daycare.

Table 4. Post-experiment interview

You have just had an experience that you have never had before. With the help of the HMD, you entered a children's world inside a computer. You were asked to do various activities. Tell us how you felt?

15. What did feel while putting on the HMD?

16. How did you feel when you were asked to climb the ladder and slide?

17. How is the feeling of viewing the world from a toddler's point of view?

18. What did you feel when the experience was over?

After undergoing this new experience, how do you think you will plan the intake of a new child into the kindergarten? How will you help him to settle in and adjust?

\subsection{Post-experiment questionnaire}

After the caregivers went through the VR experience, they were asked the same questions they have been asked before the experiment (Table 3). In 
addition, each caregiver was asked to answer the following question: How would you address differently a new infant in your day-care after going this experience.

\section{RESULTS}

\subsection{Emotional awareness}

We assumed that caregivers are not aware sufficiently to the difficulties a child goes through the separation from his parents in his first days at the kindergarten. We have tested this assumption with the direct question, which has been asked following the VR experience: what would be your attitude to a new child attending your kindergarten now that you have experienced the VR worlds?

The answers of the 40 participants indicated that:

25 of them $(62.5 \%)$ reported some type of change in their attitude towards a new child attending kindergarten. This result was found to be significant $\mathrm{t}=(8.0,39), \mathrm{p}<0.001$

12 out of these $25(48 \%)$ pointed to changes that correspond to emotional aspects ( 3 of them related to just emotional aspects and 9 to both emotional and cognitive aspects).

This assumption was fortified by the direct question; meaning that the VR experience improved the awareness of the caregivers to the toddlers' emotional experiences in the first days in kindergarten.

\subsection{Emotional awareness with and without emotional mediation}

However, the other objective of this study was to test whether experiencing VR with emotional mediation will improve the caregiver awareness to the feelings of anxiety, frustration, and need for help. The assumption was that a VR experience coupled with emotional mediation will better improve (Table 5) the emotional awareness of the caregivers to the toddler's first day's feelings in kindergarten. 
Table 5. Change in attitude

\begin{tabular}{|l|l|c|}
\hline \multirow{2}{*}{} & \multicolumn{1}{|c|}{$\begin{array}{c}\text { Experiencing feelings of fear, frustration and need for help during } \\
\text { the VR experiment }\end{array}$} \\
\cline { 2 - 3 } & \multicolumn{2}{|c|}{$\mathrm{R}$} \\
\hline $\begin{array}{l}\text { Change in attitude } \\
\text { towards a } \\
\text { newcomer infant to } \\
\text { the kindergarten }\end{array}$ & $\begin{array}{l}\text { Caregivers that received emotional } \\
\text { mediation }(\mathrm{n}=20)\end{array}$ & $-0.602 *$ \\
\cline { 2 - 3 } & $\begin{array}{l}\text { Caregivers that did not receive } \\
\text { emotional mediation }(\mathrm{n}=20)\end{array}$ & -0.101 \\
\hline
\end{tabular}

${ }^{*} \mathrm{p}<0.01$

Among the group that received emotional mediation we found a higher correlation (0-fear, anxiety, need for help; 1 - other feelings) between those that reported feelings during the VR experience and those that reported a change in attitude towards a newcomer infant to their day-care $(1$ - reported change in attitude; 0 - reported no-change) $r=-0.602<0.01$.

On the other hand, among the group that did not receive any emotional mediation, we did not find a correlation between those that reported feelings during the VR experience and those that reported a change in attitude towards a newcomer infant to their day-care.

Thus, the results clearly indicate that experiencing VR toddler's worlds with emotional mediation improved the awareness of the caregiver to the feelings that a toddler go through in his first days in kindergarten.

\section{DISCUSSION}

The purpose of this research was to test whether using a cutting edge technology - Virtual Reality - to train teachers would make an impression on the teacher, and influence her future behaviour with toddlers. The research aimed to test whether a very small investment in time (10 minutes in a toddler's simulated virtual world) would produce significant training results for the teachers.

To the best of our knowledge, this is the first research project to report positive results for such a hypothesis. Many other studies have proved the effectiveness of Virtual Reality in other training situations, but our review of the literature did not reveal any use of VR with cognitive and emotional aspects related to toddlers.

The literature offers examples of users of Virtual Reality who reported similar feelings who were influenced by the sensation of 3D immersive VR (Bricken and Byrne 1992, Shapiro and McDonald 1992). However, no report 
has been published demonstrating a simulated infant cognitive state of mind and its impact on adults.

No reliable tool was found in the literature in order to carry on this research. Therefore, different 'childhood experts' were asked to draft a list of questions that will represent (somehow) the toddlers' cognitive and emotional way of thinking. It was quite an experience to draft this list. The 'experts' (faculty members of the Baker Centre for Early Childhood Education, School of Education, Bar-Ilan University http://www.biu.ac.il) recommended a short list that would be simple enough for the participants to follow. This seems satisfactory as an initial attempt to simulate the emotional state of a toddler and test its efficiency. If not to clearly indicate the efficiency of the VR technology to enhance the awareness of the caregivers to the toddlers' emotional experience, then at least at observing evidence that count for a trend.

Following the exercise in the virtual worlds, the most noteworthy improvement in the caregivers' awareness was in relation to the fact that with some kind of emotional mediation the VR experience better improved the caregivers' awareness to the emotional state of the ttoddlers in the first days in kindergarten.

It could be that this kind of improvement stems from the caregiver's feeling as she enters the virtual world, in which she is by herself, with everything happening around her. She had to activate this virtual world, to operate and manipulate objects. It could well be that during an experience, in which everything that happens is dependent only on her, help (emotional mediation) that she is receiving emphasises her awareness to others' emotional needs.

The results of this research are by no means final, since without VR we would have had no means at all of getting the material across to the caregivers, apart from the conventional, lengthy, wearisome and expensive way - with words. This type of research opens a new path into uncharted territories - worlds that we could not easily and quickly touch and demonstrate. As opposed to other research projects using Virtual Reality, this research did not simulate situations or worlds familiar to us, but rather created abstract scenarios from a human brain, and tested the efficiency of another person's interaction with it. This study tested the immediate change in the caregivers' attitude. Further research should be conducted to test the long-range effect of VR on their behaviour. Nonetheless, this research offers tools and hope for educators that they may be able to understand what is happening in the worlds of those children under their responsibility. 


\section{REFERENCES}

Bricken, M. and Byrne, C. M. (1992) Summer students in virtual reality: a pilot study on educational application of virtual reality technology. University of Washington. Seattle, WA. [http://www.hitl.washington.edu/projects/education].

Cass, M. D. and Roblyer, M. D. (1999) A review of experimental research on virtual reality in special education: the status of the dream. VR in the Schools, 4. [http://150.216.8.1/vr/vrel.htm].

Erickson, A. (1950) Childhood and Society. Hapoalim Press, Tel Aviv, Israel (in Hebrew).

Flavell, J. H. (1970) The developmental psychology of Jean Piaget. Otsar Hamoreh, Tel Aviv (in Hebrew).

Pantelidis, V. S. (1994) Virtual Reality in the classroom. Computers in Education, 30 pp. 313, Tel Aviv (in Hebrew).

Piaget, J. (1967) The world representation of the child. Hakibutz Haarzi Publication, Tel Aviv (in Hebrew).

Psotka, J. (1995) Immersive-tutoring systems: virtual reality and education and training. US Army Research Institute, U.S.A, Alexandria, VA.

Shapiro, M. A. and MacDonald, D. G. (1992) I am not a real doctor, but I play one in virtual reality: implication of virtual reality for judgments about reality. Journal of Communication, 42, pp. 94-114.

Shechter, R. and McKoli, K. S. (1989) When Your Children are Afraid. Hadar, Tel Aviv (in Hebrew).

Srof, A., Kooper, R. and Dehart, G. (1998) Child Development: nature and course. Open University, Tel Aviv (in Hebrew).

Tal, K. (1991) Struggle with Fears in Early Childhood. Sara Batz Publication, Tel Aviv (in Hebrew).

\section{BIOGRAPHY}

David Passig is a faculty member at the Bar-Ilan University. He teaches Future Methodologies and Systems Theory, and is heading the Virtual Reality Laboratory at the graduate program of Technology \& Communication at the School of Education. His current research endeavours are: Future learning technologies and their cognitive impact, MM and VR learning interface, future cognitive and learning skills (www.passig.com). Tali Noyman is a researcher at the Virtual Reality Laboratory. 